\title{
Benchmarking the Operational Efficiency of China's Peer-to-Peer Lending Platforms Based on Data Envelopment Analysis
}

\author{
Ao Liu ${ }^{1,2}$, Xudong Deng ${ }^{1,2}$, Zeping Tong ${ }^{1,2}$, Yajuan Wang ${ }^{1,2}$, Liang Ren ${ }^{1,2}$ \\ 1. School of Management, Wuhan University of Science and Technology, Wuhan, China \\ 2. Center for Service Science and Engineering, Wuhan University of Science and Technology, Wuhan, China \\ Corresponding Author: liuao@amss.ac.cn
}

\begin{abstract}
As a new financial loan model, peer-to-peer (P2P) lending has been widely spread across the world since emerging, especially in China. However, it often involves risk events, including difficult cash withdrawal, escaping with money, financial fraud, and trouble management etc. Therefore, how to evaluate its operational efficiency and determine a good platform plays a vital role in the operation of P2P lending platforms, which is also valuable for inexperienced lenders. In this paper, a data envelopment analysis (DEA) method was applied for measuring operational efficiency so as to separate efficient and inefficient P2P platforms in China. The results indicated that on the basis of the CCR model, the ratio of efficient and inefficient units in 60 platforms was $40 \%$ and $60 \%$ respectively; and the average of technical, pure technical and scale efficiencies of inefficient units were $0.700, \quad 0.842, \quad 0.800$ respectively, which demonstrated that most of the difference between in efficient and inefficient units lies in the return to scale. The results also suggested the efficient benchmarking targets to guide inefficient units toward the efficient units.
\end{abstract}

Keywords-Peer-to-peer lending; Efficiency evaluation; Data envelopment analysis; Benchmarking

\section{INTRODUCTION}

As a novel loan model, peer-to-peer lending (P2P) has emerged and been spread widely in the world, which aims to bridge the gap and mismatch between supply and demand of the finical loan market. Since the world first P2P lending platform Zopa has launched at London in 2005, P2P lending has attracted considerable attention from both the academy and industrial specialists in the field of economic, finance, computer science, etc [1].

$\mathrm{P} 2 \mathrm{P}$ lending aims to mitigate information asymmetries and match the financial demand between both lenders and borrowers, which is expected to eliminate expensive intermediaries and reduce transaction costs through online platforms [2-3].

Although P2P lending is an emergent phenomenon, there is an increasing amount of literature concerning this topic. For instance, some researchers address roles and impact of social networks on P2P lending. Freedman [4] suggested that, in Prosper, lenders can obtain some soft information about the default risk from the borrowers' social networks in order to compensate for the lack of hard information. Besides, Herzenstein et al [5] found that borrower attributes such as demographic characteristics, financial strength, and effort prior to making the request affect the likelihood of funding success as well as financial strength. Chen et al.[6] investigated the relationship between individuals' group social capital and their lending outcomes in P2P lending, which found that the borrower's general group social capital and relational social capital yielded inconsistent effects, and the borrower's structural social capital had a negative impact on their funding and repayment performance.

In addition, the existence of $\mathrm{P} 2 \mathrm{P}$ lending's information asymmetry resulted in herding behaviors, which described the situation that an individual could make the decisions by following the decisions of others. Lee and Lee [7] employed multinomial logit market-share model to empirically investigate herding behavior in the $\mathrm{P} 2 \mathrm{P}$ lending market in Korea, and found strong evidence of herding and its diminishing marginal effect as bidding advances. Zhang and Liu [8] used the panel data of Prosper to examine herding behavior, and showed that rational herding beats irrational herding in predicting loan performance. Zhang and Chen [9] further investigated the loan requests in RenRenDai and found evidence for the existence of both rational and irrational herding in the $\mathrm{P} 2 \mathrm{P}$ lending market.

Some researchers also pay attention to other issues, including discrimination, default risk, credit scoring, and decision aid et al [10-13]. Pope and Sydnor [10] found evidence of significant racial disparities in P2P lending, where loan listings with blacks were 25 to 35 percent less likely to receive funding than those of whites with similar credit profiles. Guo et al. [11] studied the credit risk assessment and investment portfolio in P2P lending. They proposed an instance-based credit risk assessment model. The results demonstrated the superiority of instance-based risk assessment model. Serrano and Gutiérrez [12] proposed a P2P lending profit scoring system so as to estimate loan default probability. The results indicated that a lender's outcome by applying a profit scoring system outperforms the outcome obtained by using a logistic regression-based credit scoring system. Puro et al [13] addressed the borrower decision aid to help the borrower to quantify his strategic options, such as starting interest rate, and the amount of loan requested. Dorfleitner et al.[14] investigated the relation of soft factors derived from the description texts to the probability of successful funding and the default probability for two European P2P lending platforms, which found that spelling errors, text length and positive emotion evoking keywords predict the funding probability on the less restrictive of both platforms; conditional on being funded, text-related factors hardly predict default probabilities in peer-to-peer lending for both platforms.

In the aforementioned literatures, plenty of researchers have paid considerable attention to peer-to-peer lending, most of these research efforts focus on peer-to-peer social 
networks, micro herding behaviors, discrimination, default risk, et al, which can help one to understand the micro economics as well as operation dynamics of P2P lending. However, there are few research efforts focusing on macro operational efficiency of P2P lending platforms, which affects the business potential of $\mathrm{P} 2 \mathrm{P}$ lending, involvement of lenders and borrowers, and the daily operation of $\mathrm{P} 2 \mathrm{P}$ lending platforms.

Actually, in one hand, despite of P2P lending's popularity and advantages, it often suffers from risk events, including difficult cash withdrawal, escaping with money, financial fraud, and trouble management, et al; in other hand, the long-term success of $\mathrm{P} 2 \mathrm{P}$ lending platforms relies on its operational efficiency. Moreover, it's difficult for inexperienced lenders to judge the quality of the loans, because lenders "bear the default risk and few of them are experts in risk management ", which will affect the lenders' willingness to make investment decisions across numerous P2P lending platforms [15].

Hence, a scientific and reasonable analysis of operation efficiency is needed to assess the operational capability and the future business potential of online peer-to-peer lending platforms as well as guide the lender to choose a good P2P platform and make an investment decision. This paper is going to address the issue of operation efficiency assessment, which aims to help us identify both the efficient and inefficient platforms, and then improve the inefficient platforms' efficiency by benchmarking efficient targets.

The rest of the paper is organized as follows. Section II presents a brief introduction of data envelope analysis (DEA) and the classical CCR model. Section III carries out DEA-based empirical study and discussed the results after describing the sampling data and giving some descriptive statistical analysis. In section IV, we give some conclusion remarks by presenting limitations and future research.

\section{DATA ENVELOPEMENT ANALYSIS}

Data envelope analysis (DEA) is firstly proposed by Charmes, Cooper, and Rhodes, and named as CCR model, which is a non-parametric approach to estimate efficiency frontiers in multi-input and multi-output systems [16-17].

With loss of generality, consider an input-output system with $n$ DMUs, each DMU consumes $m$ inputs and produces $S$ different outputs. DMU $k$ consumes amounts $x_{i j}$ of the $i^{\prime}$ th input $(i=1,2, \cdots, m)$ and produces amounts $y_{r j}$ of the $j^{\prime}$ th output $(j=1,2, \cdots, s)$.

The basic idea of DEA is to find the optimal weights so as to maximize the ratio of the sum of weighted inputs to the sum of weighted outputs for any DMU.

\section{A. CCR model}

The input-oriented CCR model is defined as follows [16], the efficiency of DMU $k$ is $\theta^{*}$ :

$$
\begin{gathered}
\theta^{*}=\min \theta \\
\text { s.t. }\left\{\begin{array}{l}
\sum_{i=1}^{n} \lambda_{j} x_{i j}+s_{i}^{-}=\theta x_{i k}, i=1,2, \cdots, m \\
\sum_{i=1}^{n} \lambda_{j} y_{r j}-s_{r}^{+}=y_{r k}, r=1,2, \cdots, s \\
\lambda_{j} \geq 0, j=1,2, \cdots, n \\
s_{i}^{-} \geq 0, i=1,2, \cdots, m \\
s_{r}^{+} \geq 0, r=1,2, \cdots, s
\end{array}\right.
\end{gathered}
$$

where, ${ }^{+}{ }_{r}^{+}$and $s_{i}^{-}$denote the extra amounts reduced (or increased) by an input (or output) to be efficient.

\section{B. BCC model}

Banker et al.[17] introduced BCC model in order to measure the variable returns to scale.

The BCC model is presented as follows:

$$
\begin{gathered}
\theta^{*}=\min \theta \\
\text { s.t. }\left\{\begin{array}{l}
\sum_{i=1}^{n} \lambda_{j} x_{i j}+s_{i}^{-}=\theta x_{i k}, i=1,2, \cdots, m \\
\sum_{i=1}^{n} \lambda_{j} y_{r j}-s_{r}^{+}=y_{r k}, r=1,2, \cdots, s \\
\sum_{i=1}^{n} \lambda_{j}=1 \\
\lambda_{j} \geq 0, j=1,2, \cdots, n \\
s_{i}^{-} \geq 0, i=1,2, \cdots, m \\
s_{r}^{+} \geq 0, r=1,2, \cdots, s
\end{array}\right.
\end{gathered}
$$

\section{DEA Efficiency}

Definition (DEA Efficiency) [18-19]: A DMU is fully efficient if and only if both $\theta^{*}=1$ and all slacks $s_{i}^{-}=s_{r}^{+}=0$.

Definition 2 (Weakly DEA Efficient) $[18,19]$ : A DMU is weakly efficient if and only if both $\theta^{*}=1$ and $s_{i}^{-} \neq 0$ or $s_{r}^{+} \neq 0$ for some $i$ or $r$.

So, all of the DMUS can be classified into two sets of efficient and inefficient units by CCR model; the inefficient units can be ranked according to their efficiency scores.

Furthermore, BCC model gives the pure technical efficiency (PTE) of DMUs without any scale effect, while CCR measures the technical efficiency (TE), which is a product of pure technical efficiency (PTE) and scale efficiency (SE).

The scale efficiency can be derived as follows:

$$
S E=\frac{T E}{P T E}
$$

\section{EMPIRICAL STUDY}

In this section, some input and output indicators were defined, and then an empirical study about 60 P2P platform's operation efficiency will be carried out, where a data sampling and collection was presented, followed by a simple descriptive statistical analysis. Furthermore, a detailed DEA-based operational efficiency assessment was investigated.

\section{A. The input and output indicators}

In this section, we will define the input and output indicators in order to describe each DMU's characteristics and make the operational efficiency assessment for the DMUs, which refer to the P2P lending platforms in China. 
According to the empirical study of DEA, the total number of input and output indicators should be at most $20 \%$ of the number of the DMUs. In this study, we will assess the operation efficiency of $60 \mathrm{P} 2 \mathrm{P}$ lending platforms in China. Moreover, DEA generally regards the income index as the output indicator, while regarding the cost index as input indicator.

The input and output indicators of the P2P lending platforms are listed in the TABLE I:

TABLE I. INDICATORS FOR P2P LENDING PLATFORMS IN CHINA

\begin{tabular}{ccc}
\hline Type & Indicators & Description \\
\hline \multirow{4}{*}{ Input } & X1 & Total amount of registered capital (TRC) \\
& X2 & Total operating hours (TOH) \\
& X3 & Total number of investors (TNI) \\
& X4 & The average investment amount per investor (AII) \\
X5 & The average investment times per investor (AIT) \\
\hline \multirow{3}{*}{ Output } & Y1 & Total trading volume (TDV) \\
& Y3 & Total number of borrowers (TNB) \\
& Y4 & The average loan amount per borrower (ALB) \\
& Y5 & The average loan times per borrower (ALT)
\end{tabular}

B. Descriptive statistical analysis

In this section, we collect sampling data of $60 \mathrm{P} 2 \mathrm{P}$ lending platforms in China from the homepage of 01caijing, and then carry out a simple descriptive statistical analysis, which is summarized and depicted in TABLE III.

As seen from TABLE II, TRC, TNI, TDV, TNB and ALB has obvious high standard deviation. Intuitively, this observation tells us that the DMUs have significant differences in these indicators. We can also see that AIR has low standard deviation, which shows us that the DMUs have no significant differences in the average interest rate to attract more potential investors. Therefore, more attentions have to be paid on the indicators with high standard deviation, which would result in heterogeneous operation efficiency between the P2P lending platforms.

TABLE II. DESCRIPTIVE STATISTICAL ANALYSIS OF THE DATA

\begin{tabular}{ccccc}
\hline Indicators & Min & Max & Mean & Std. dev \\
\hline X1 (TRC) & 100.00 & 20000.00 & 3883.21 & 3796.89 \\
X2 (TOH) & 424.00 & 3012.00 & 1107.30 & 433.45 \\
X3 (TNI) & 1.00 & 146491.00 & 11901.23 & 29701.26 \\
X4 (AII) & 0.94 & 169.30 & 13.82 & 27.21 \\
X5 (AIT) & 1.14 & 467.81 & 17.12 & 62.31 \\
Y1 (TDV) & 20.00 & 803542.00 & 53329.13 & 140586.05 \\
Y2 (TNB) & 1.00 & 785748.00 & 37450.87 & 131288.59 \\
Y3 (ALB) & 0.24 & 10498.00 & 403.41 & 1448.83 \\
Y4 (TLT) & 1.00 & 466.00 & 24.03 & 77.31 \\
Y5 (AIR) & 0.07 & 0.21 & 0.12 & 0.04
\end{tabular}

C. Identifying efficient and inefficient platforms

In this section, we make operation efficiency analysis by utilizing both CCR model and BCC model, which aim to identify efficient and inefficient platforms.

In general, CCR model can provide technical efficiency (TE) that measures the DMU's ability to produce a maximum output with a certain level of input [18], while BCC model can provide only pure technical efficiency (PTE) with variable returns to scale [19].

In the following discussion, CCR model was employed to assess technical efficiency (TE), while BCC model was utilized to measure pure technical efficiency (PTE). Moreover, according to Eq. (3), one can easily obtain scale efficiency (SE) with TE and PTE.

In TABLE III, we present the detailed efficiency of 60 units, including technical efficiency (TE), pure technical efficiency (PTE), scale efficiency (SE) and returns to scale (RTS). In the column "RTS", 1/-1/0 mean that a DMU is increasing/decreasing/constant returns to scale.
It should be noted that the higher the efficiency is, the more efficient the platform is. If the efficiency of a DMU equals to one, it means the DMU is efficient; otherwise, the DMU is inefficient, which need to improve its efficiency by some adjustment toward the input or output.

As seen from TABLE III and TABLE IV, we can draw the following conclusions:

On the basis of CCR model, from 60 P2P lending platforms, there were 24 DMUs $(40 \%)$ that had technical efficiency (TE) score of 1, which means that these DMUs is DEA efficient; while 36 DMUs $(60 \%)$ obtained their technical efficiency score less than 1 , which means that these DMUs were regarded as inefficient. In TABLE III, the DEA inefficient DMUs were labeled as bold;

on the basis of BBC model, 32 DMUs (53\%) had the pure technical efficiency (PTE) score of one that these DMUs were technical efficient; these technical efficient can further be classified two groups: one group, including DUM 20, DMU 22, DMU 30, DMU 43, DMU45, DMU 46, DMU 49 and DMU 56, was technical efficient but not DEA efficient, another group of 24 DMUs was both technical 
efficient and DEA efficient; the rest of 28 DUMs gained pure technical efficiency (PTE) score less than one, which were both DEA inefficient and technical inefficient;

in the view point of scale efficiency, 26 DMUs (43\%) were scale efficient that their scale efficiency (SE) scores equals to one, the rest of 34 DMUs were scale inefficient;

24 DMUs had efficiency scores of one for all 3 types of TE, PTE, and SE, which could be considered as excellent DMUs, while that was acceptable scores between 0.85 and 1 and scores under 0.85 were evaluated worst;

25 DMUs were in constant return to scale under the reasonable scale, 33 DMUs were in increasing return to scale, which should need extra more inputs, DMU 39 and DMU 45 were in decreasing return to scale, which should need even less input.
Moreover, description statistical results of technical efficiency (TE), pure technical efficiency (PTE), and scale efficiency (SE) are summarized in TABLE V. Additionally, Figure 1 and Figure 2 describe the efficiency score distribution of 60 P2P lending platforms.

The results demonstrated that the average technical efficiency, pure technical efficiency, and scale efficiency of 60 DMUs were $0.824,0.926$, and 0.884 , respectively. The pure technical efficiency of all units had the best average score 0.926 between technical efficiency, pure technical efficiency, and scale efficiency.

TABLE III. THE TECHNICAL (TE), PURE TECHNICAL EFFICIENCY AND SCALE EFFICIENCY OF 60 PLATFORMS

\begin{tabular}{|c|c|c|c|c|c|c|c|c|c|}
\hline DMU & $\mathrm{TE}$ & PTE & SE & RTS & DMU & TE & PTE & SE & RTS \\
\hline DMU 1 & 0.711 & 0.833 & 0.853 & 1 & DMU 31 & 0.812 & 0.914 & 0.888 & 1 \\
\hline DMU 2 & 1.000 & 1.000 & 1.000 & 0 & DMU 32 & 0.876 & 0.958 & 0.914 & 1 \\
\hline DMU 3 & 1.000 & 1.000 & 1.000 & 0 & DMU 33 & 1.000 & 1.000 & 1.000 & 0 \\
\hline DMU 4 & 1.000 & 1.000 & 1.000 & 0 & DMU 34 & 0.624 & 0.875 & 0.713 & 1 \\
\hline DMU 5 & 1.000 & 1.000 & 1.000 & 0 & DMU 35 & 0.368 & 0.780 & 0.472 & 1 \\
\hline DMU 6 & 1.000 & 1.000 & 1.000 & 0 & DMU 36 & 0.782 & 0.957 & 0.817 & 1 \\
\hline DMU 7 & 1.000 & 1.000 & 1.000 & 0 & DMU 37 & 1.000 & 1.000 & 1.000 & 0 \\
\hline DMU 8 & 0.963 & 0.963 & 1.000 & 0 & DMU 38 & 1.000 & 1.000 & 1.000 & 0 \\
\hline DMU 9 & 1.000 & 1.000 & 1.000 & 0 & DMU 39 & 0.861 & 0.894 & 0.963 & -1 \\
\hline DMU 10 & 0.533 & 0.628 & 0.850 & 1 & DMU 40 & 0.639 & 0.926 & 0.690 & 1 \\
\hline DMU 11 & 0.450 & 0.505 & 0.892 & 1 & DMU 41 & 0.593 & 0.748 & 0.793 & 1 \\
\hline DMU 12 & 0.751 & 0.922 & 0.814 & 1 & DMU 42 & 1.000 & 1.000 & 1.000 & 0 \\
\hline DMU 13 & 0.866 & 0.953 & 0.909 & 1 & DMU 43 & 0.832 & 1.000 & 0.832 & 1 \\
\hline DMU 14 & 0.655 & 0.674 & 0.972 & 1 & DMU 44 & 0.633 & 0.779 & 0.813 & 1 \\
\hline DMU 15 & 0.814 & 0.819 & 0.994 & 1 & $\underline{D M U} 45$ & $\underline{0.892}$ & $\underline{1.000}$ & 0.892 & -1 \\
\hline DMU 16 & 1.000 & 1.000 & 1.000 & 0 & $\overline{D M U ~ 46}$ & 0.576 & 1.000 & 0.576 & 1 \\
\hline DMU 17 & 0.453 & 0.731 & 0.619 & 1 & $\overline{\text { DMU } 47}$ & 0.646 & 0.926 & 0.698 & 1 \\
\hline DMU 18 & 1.000 & 1.000 & 1.000 & 0 & DMU 48 & 0.825 & 0.991 & 0.833 & 1 \\
\hline DMU 19 & 0.791 & 0.954 & 0.829 & 1 & $\underline{D M U} 49$ & $\underline{0.773}$ & $\underline{1.000}$ & $\underline{0.773}$ & 1 \\
\hline$\underline{D M U} 20$ & 0.800 & 1.000 & $\underline{0.800}$ & 1 & $\overline{\text { DMU } 50}$ & 0.606 & 0.741 & $\overline{0.817}$ & 1 \\
\hline$\overline{\text { DMU } 21}$ & 0.535 & $\overline{0.762}$ & 0.702 & 1 & DMU 51 & 1.000 & 1.000 & 1.000 & 0 \\
\hline$\underline{D M U} 22$ & $\underline{0.876}$ & $\underline{1.000}$ & $\underline{0.876}$ & 1 & DMU 52 & 1.000 & 1.000 & 1.000 & 0 \\
\hline DMU 23 & 1.000 & 1.000 & 1.000 & 0 & DMU 53 & 1.000 & 1.000 & 1.000 & 0 \\
\hline DMU 24 & 0.590 & 0.933 & 0.633 & 1 & DMU 54 & 1.000 & 1.000 & 1.000 & 0 \\
\hline DMU 25 & 0.524 & 0.980 & 0.535 & 1 & DMU 55 & 1.000 & 1.000 & 1.000 & 0 \\
\hline DMU 26 & 1.000 & 1.000 & 1.000 & 0 & $\underline{\text { DMU } 56}$ & $\underline{0.937}$ & $\underline{1.000}$ & $\underline{0.937}$ & 1 \\
\hline DMU 27 & 0.883 & 0.894 & 0.988 & 1 & DMU 57 & 1.000 & 1.000 & 1.000 & 0 \\
\hline DMU 28 & 0.522 & 0.858 & 0.608 & 1 & DMU 58 & 1.000 & 1.000 & 1.000 & 0 \\
\hline DMU 29 & 0.559 & 0.685 & 0.815 & 1 & DMU 59 & 1.000 & 1.000 & 1.000 & 0 \\
\hline$\underline{D M U} 30$ & 0.902 & 1.000 & 0.902 & 1 & DMU 60 & 1.000 & 1.000 & 1.000 & 0 \\
\hline
\end{tabular}


TABLE IV. THE EFFICIENCY SCORES DISTRUBUTION RESULT OF 60 P2P LENDING PLATFORMS

\begin{tabular}{lllllll}
\hline Efficiency & TE & \multicolumn{3}{c}{ PTE } & SE & \\
\cline { 2 - 7 } Interval & Frequencies & Ratio & Frequencies & Ratio & Frequencies & Ratio \\
\hline $0.35-0.45$ & 7 & 0.12 & 1 & 0.02 & 2 & 0.03 \\
$0.45-0.55$ & 9 & 0.15 & 1 & 0.02 & 4 & 0.07 \\
$0.55-0.65$ & 2 & 0.03 & 5 & 0.08 & 4 & 0.07 \\
$0.65-0.75$ & 9 & 0.15 & 5 & 0.08 & 12 & 0.20 \\
$0.85-0.95$ & 8 & 0.13 & 9 & 0.15 & 9 & 0.15 \\
$0.95-0.99$ & 1 & 0.02 & 6 & 0.10 & 3 & 0.05 \\
$0.99-1.00$ & 24 & 0.40 & 33 & 0.55 & 26 & 0.43 \\
\hline
\end{tabular}

Furthermore, the average pure technical efficiency of inefficient units was 0.842 , while the average technical efficiency and scale efficiency of inefficient units were 0.700 and 0.800 , which indicated that these units performs better in technical practices, and most of the difference between in efficient and inefficient units lies in the return to scale. These results also revealed that if the inefficient units could adjust return to scale toward the best scale, it's possible to improve their efficiency with little change in technological practices

TABLE V. THE SUMMARIZED RESULTS OF TE, PTE, AND SE

\begin{tabular}{cccccc}
\hline DMUs & Efficiency & Min & Max & Mean & Std \\
\hline & TE & 0.368 & 1.000 & 0.824 & 0.189 \\
All DMUs & PTE & 0.505 & 1.000 & 0.926 & 0.115 \\
& SE & 0.472 & 1.000 & 0.884 & 0.141 \\
\hline \multirow{2}{*}{ Inefficient } & TE & 0.368 & 0.963 & 0.700 & 0.156 \\
DMUs & PTE & 0.505 & 0.991 & 0.842 & 0.123 \\
& SE & 0.472 & 0.994 & 0.800 & 0.132 \\
\hline
\end{tabular}

\section{Benchmarks for P2P lending platforms}

In this section, we will present the benchmarks that aim to help each DMU to be efficient. In DEA model, the efficient DMUs are selected as reference set and guide other inefficient DMUs toward them [20]. The technical efficiency of DMUs 1-10 and their benchmark sets are shown in TABLE VI, where the technical efficiency of DMUs 1-10, their benchmarks and corresponding weights were depicted in details.

As seen from TABLE VI, for each of DMUs 1-10, the units that their technical efficiency equal to one are efficient, while their technical efficiency less than one are inefficient. Generally, in DEA's benchmarking, the efficient units or their combination can be selected as the best following benchmark units by inefficient units.
In other words, inefficient units can be efficient if it is composed of several efficient units instead of using a single unit as a benchmark. For example, the benchmark units of DMU 8 is labelled as 3(0.142) 57(0.842) 2(0.027), where 3, 57 and 2 are the benchmarking DMUs while the values between brackets are the corresponding weights for the benchmarking DMU 3, 57, and 2, respectively.

Besides, these benchmarks provide directional targets for business operational teams of $\mathrm{P} 2 \mathrm{P}$ lending platforms to balance the input and output. By selecting these efficient units as benchmarks, inefficient units can determine the corresponding decrements (or increment) of the current input and output for benchmarking in order to establish the best practice management and achieve excellent efficiency from an operational efficiency point of view.

TABLE VI. THE BENCHMARKS AND CORRESPONDING WEIGHTS OF DMUS 1-10

\begin{tabular}{|c|c|c|c|c|c|c|c|c|}
\hline DMU & $\mathrm{TE}$ & Benchmarl & nd weights & & & & & \\
\hline 1 & 0.71 & $7(0.076)$ & $57(0.155)$ & $3(0.045)$ & $26(0.019)$ & $2(0.059)$ & $4(0.167)$ & $55(0.18)$ \\
\hline 2 & 1.00 & $2(1)$ & & & & & & \\
\hline 3 & 1.00 & $3(1)$ & & & & & & \\
\hline 4 & 1.00 & $4(1)$ & & & & & & \\
\hline 5 & 1.00 & $5(1)$ & & & & & & \\
\hline 6 & 1.00 & $6(1)$ & & & & & & \\
\hline 7 & 1.00 & $7(1)$ & & & & & & \\
\hline 8 & 0.96 & $3(0.142)$ & $57(0.842)$ & $2(0.027)$ & & & & \\
\hline 9 & 1.00 & $9(1)$ & & & & & & \\
\hline 10 & 0.53 & $55(0.648)$ & $26(0.001)$ & $4(0.079)$ & $7(0.026)$ & & & \\
\hline
\end{tabular}




\section{CONCLUSION}

In recent years, peer-to-peer (P2P) lending has emerged and garnered increasing attention from the academic researchers and industrial specialists. Despite of its popularity, P2P lending often suffers from varying risk events. It's a challenge task to identify a good platform for both the borrowers and the lenders, which would affect their willingness to involve into $\mathrm{P} 2 \mathrm{P}$ lending. In this paper, a data envelope analysis (DEA) based method is employed to assess the operational efficiency of P2P lending and identify the efficient and inefficient platforms, where 10input and output indicators are chosen to measure efficiency of P2P lending platforms. Then, on the basis of $60 \mathrm{P} 2 \mathrm{P}$ platforms' sampled data, both CCR model and BCC model are utilized to assess their operational efficiency, including technical efficiency (TE), pure technical efficiency (PTE), and scale efficiency (SE).

From the aforementioned analysis, we draw some conclusions about the operation efficiency of P2P lending platforms in China: firstly, from the view point of technical efficiency, in total $60 \mathrm{P} 2 \mathrm{P}$ lending platforms, 24 platforms $(40 \%)$ are efficient, while 36 platforms $(60 \%)$ are inefficient; secondly, from the view point of pure technical efficiency, 8 platforms are technical efficient but not DEA efficient, 24 platforms are both technical efficient and DEA efficient, the rest of 28 platforms were both DEA inefficient and technical inefficient; thirdly, 25 platforms were in constant return to scale, 33 platforms were in increasing return to scale, and 2 platforms were in decreasing return to scale. The results further demonstrated that most of the difference between in efficient and inefficient units lies in the return to scale; finally, we gave some benchmarking units and corresponding weights of inefficient DMUs 1-10 to provide the targets to inefficient units and guide them toward the efficient targets.

In this paper, the main contributions lie in two points. Firstly, it is beneficial to assess operational efficiency of P2P lending platforms in China; secondly, via both the quantitative CCR model and BCC model, it is helpful to identify efficient and inefficient platforms and guide the inefficient units toward their efficient benchmarking targets so as to avoid redundant inputs and insufficient outputs.

In the future work, it's worth developing dynamic analysis by Malmquist index [21], taking undesirable outputs into consideration in DEA, devoting on random inputs and output by stochastic frontier analysis [22].

\section{ACKNOWLEDGMENT}

The authors gratefully acknowledge the helpful comments of anonymous referees.

This research was supported by National Natural Science Foundation of China under Grant No. 71701156, and 71601150, Natural Science Foundation of Hubei Province of China under Grant No. 2017CFB427, Humanity and Social Science Youth Foundation of Ministry of Education of China under Grant No. 16YJCZH056, Hubei Province Department of Education Humanities and Social Sciences Research Project under Grant No. 17Q034, Open Funding of Center for Service Science and Engineering, Wuhan University of Science and Technology under Grant No. CSSE2017KA01, Open Funding of Intelligent Information Processing and Real-time Industrial System under Grant No. 2016znss18B, Young Incubation Program of Wuhan University of Science and Technology under Grant No. 2016xz017 and $2017 \mathrm{xz} 031$.

\section{REFERENCES}

[1] M. Klafft, "Online peer-to-peer lending: a lenders' perspective", in 2008 International Conference on E-Learning, E-Business, Enterprise Information Systems, and E-Government, Las Vegas, Nevada, 2008, pp. 371-375.

[2] M. Klafft, "Peer-to-peer lending: auctioning microcredits over the internet", in Proceedings of the 2008 International Conference on Information Systems, Technology and Management, IMT, Dubai 2008, pp. 185-190.

[3] H. Wang, M. Greiner, J. E. Aronson, "People-to-people lending: the emerging E-commerce transformation of a financial market ", Lecture Notes in Business Information Processing, Vol. 36, 2009, pp. 182-195.

[4] S. Freedman, G. Z. Jin, "Do social networks solve information problems for peer-to-peer lending? Evidence from Prosper.com", Working Paper, The Krannert School, Purdue University, 2008.

[5] M. Herzenstein, R. L. Andrews, U. M. Dholakia, et al, "The democratization of personal consumer loans? Determinants of success in online peer-to-peer lending communities", Bulletin of the University of Delaware, Vol. 15, No. 3, 2008, pp. 274-277.

[6] X. Chen, L. Zhou, D. Wan, "Group social capital and lending outcomes in the financial credit market", Electronic Commerce Research \& Applications, Vol. 15, 2016, pp. 1-13.

[7] E. Lee, B. Lee, "Herding behavior in online P2P lending: an empirical investigation", Electronic Commerce Research and Applications, Vol. 11, No. 5, 2012, pp. 495-503.

[8] J. Zhang, P. Liu, "Rational herding in microloan markets", Management Science, Vol. 58, No. 5, 2012, pp. 892-912.

[9] K. Zhang, X. Chen, "Herding in a P2P lending market: rational inference or irrational trust?", Electronic Commerce Research and Applications, Vol. 23, 2017, pp. 45-53.

[10] D. G. Pope, J. R. Sydnor, "What's in a picture?: evidence of discrimination fromprosper.com", Journal of Human Resources, Vol. 46, No. 1, 2011, pp. 53-92.

[11] Y. Guo, W. Zhou, C. Luo, et al, "Instance-based credit risk assessment for investment decisions in P2P lending", European Journal of Operational Research, Vol.249, No. 2, 2015, pp. 417-426.

[12] C. C. Serrano, N. B. Gutiérrez, "The use of profit scoring as an alternative to credit scoring systems in peer-to-peer (P2P) lending", Decision Support Systems, Vol. 89, 2016, pp. 113-122.

[13] L. Puro, J. E. Teich, H. Wallenius, et al, "Borrower decision aid for people-to-people lending", Decision Support Systems, Vo. 49, No. 1 , 2010, pp. 52-60.

[14] G. Dorfleitner, Priberny C, Schuster S, et al, "Description-text related soft information in peer-to-peer lending-Evidence from two leading European platforms", Journal of Banking \& Finance, Vol. 64, 2016, pp. 169-187.

[15] S. Heng, T. Meyer, A. Stobbe, "Implications of Web 2.0 for financial institutions: be a driver, not a passenger", Economics, Vol. 63, 2007, pp. 1-10.

[16] A. Charnes, W. W. Cooper, E. Rhodes, "Measuring the efficiency of decision making units", European journal of operational research, Vol. 2, No. 6, 1978, pp. 429-444.

[17] R. D. Banker, A, Charnes, W. W. Cooper, "Some models for estimating technical and scale inefficiencies in data envelopment analysis", Management science, Vol. 30, No. 9, 1984, pp. 1078-1092.

[18] W. W. Cooper, L. M. Seiford, J. Zhu. Data envelopment analysis: history, models, and interpretations in Handbook on Data Envelopment Analysis, Springer, US: 2011, pp. 1-39.

[19] S. M. Nassiri, S. Singh, "Study on energy use efficiency for paddy crop using data envelopment analysis (DEA) technique", Applied Energy, Vol. 86, No. 7, 2009, pp. 1320-1325.

[20] N. Adler, L. Friedman, Z. S. Stern, "Review of ranking methods in the data envelopment analysis context", European Journal of Operational Research, Vol. 140, No. 2, 2002, pp. 249-265.

[21] Z. Li, J. Crook, G. Andreeva, "Dynamic prediction of financial distress using Malmquist DEA", Expert Systems with Applications, Vol. 80, 2017, pp. 94-106.

[22] H. Katuwal, D. E. Calkin. "Production and efficiency of large wildland fire suppression effort: a stochastic frontier analysis", Journal of environmental management, Vol. 166, 2016, pp. 227-236. 